\title{
Sobre a Coesão do Texto dos Surdos aos Olhos dos Ouvintes: $O$ uso das marcas de oralidade na escrita
}

\author{
Wagner Teobaldo Lopes de Andrade \\ Universidade Federal da Paraíba \\ Marígia Ana de Moura Aguiar \\ Francisco Madeiro \\ Universidade Católica de Pernambuco \\ Sandra Patrícia Ataíde Ferreira \\ Antonio Roazzi \\ Universidade Federal de Pernambuco
}

\begin{abstract}
RESUMO
O fato de os surdos utilizarem a língua de sinais, que lhes promove naturalmente o acesso ao conhecimento, em geral, leva a dificuldades para ler e escrever, tendo em vista que esta leitura e esta escrita são produzidas em uma língua que não é a sua: a língua padrão do país. Sendo as marcas de oralidade favorecedoras da coesão textual, a pergunta norteadora deste estudo foi: o fato de utilizar marcas de oralidade na escrita faz com que esta seja mais compreensível? Objetivou-se, portanto, investigar a compreensão, por ouvintes, do texto escrito por surdos, em função da ocorrência de tais marcas na escrita. Fragmentos de escrita com mais de uma marca, com uma marca e sem marca de oralidade, produzidos por surdos, além de fragmentos produzidos por ouvintes, foram apresentados a estudantes universitários ouvintes, que atribuíram escores aos fragmentos em função da compreensão do conteúdo. Foi verificado que os fragmentos referidos como de conteúdo mais compreendido foram os produzidos por ouvintes, seguidos dos com mais de uma marca de oralidade produzidos por surdos; os menos compreendidos foram os sem marca de oralidade produzidos por surdos. $\mathrm{O}$ estudo sugere que as marcas de oralidade promoveram a coesão textual dos surdos, facilitando a compreensão do conteúdo da sua escrita por ouvintes.
\end{abstract}

Palavras-chave: surdez; oralidade; escrita; coesão textual.

\section{ABSTRACT \\ Text Cohesion by the Deaf as Seen by the Hearer: The use of oral cues in written texts}

The use of sign language by the deaf, though a means of providing access to knowledge, offers some specific difficulties on reading/writing due to the impossibility on acquiring the written code of the official spoken language. Taking into account that some oral cues favor textual cohesion, the question this paper is mainly concerned with is whether the use of oral cues in writing favors comprehension as well. The aim of this research was to offer written texts produced by the deaf to the non deaf to see how the text was understood by these speakers. Some written fragments contained two or more oral cues, some with just one cue or with no cues produced by the deaf and some texts produced by the non deaf were offered to university hearing students who were asked to score the texts by means of levels of comprehension. The results showed that the answers favored the texts produced by the non deaf people followed by those with more than two oral cues produced by the deaf; the texts that offered difficulty for comprehension were those with no oral cues produced by the deaf. This paper suggests that the oral cues bring cohesion to the texts produced by the deaf thus favoring the hearer text comprehension.

Keywords: deafness; oral cues; writing; text cohesion.

A surdez é uma condição que dificulta o desenvolvimento da linguagem falada e escrita em função da falta de feedback auditivo. Neste contexto, a língua de sinais é utilizada por muitos surdos para a comunicação interpessoal (com outros surdos e com ouvintes que tem conhecimento sobre a língua) e para o desen- 
volvimento educacional (aquisição de habilidades escolares, como a escrita) e cognitivo (Russo, 1999).

Este estudo parte do pressuposto de que a língua de sinais é importante para o surdo, permitindo-lhe um desenvolvimento de linguagem satisfatório em termos de efetividade comunicativa (Quadros, 1997). A comunicação dos surdos com os ouvintes, no entanto, é difícil, pelo fato de não compartilharem uma língua em comum. Por isso, estudos recentes em surdez (Andrade, 2007; Cabral, 2005; Cavalcanti, 2001; Costa, 2002; Fernandes, 2003; Friães \& Pereira, 2000; Goldfeld, 2002; Sampaio, 2004/2007) têm relevado as habilidades de escrita como um importante instrumento para a comunicação dos surdos com o mundo ouvinte (desenvolvimento linguístico) e para a aquisição do conhecimento dos estudantes surdos (desenvolvimento cognitivo), assim como para a interação social destes sujeitos. No entanto, percebe-se, empiricamente, que o fato de o surdo utilizar a língua de sinais como primeira língua ${ }^{1}$ pode levar a dificuldade para ler e escrever, tendo em vista que os textos consumidos e produzidos por eles são apresentados em uma língua que não é a sua de domínio: a língua padrão do país, no caso do Brasil, a língua portuguesa.

É fato que os ouvintes aprendem a língua padrão do país através do contato auditivo com o meio ambiente (Aimard, 1998). Tendo em vista a impossibilidade do processo de aquisição de forma semelhante pelos surdos, a língua portuguesa acaba sendo ensinada a esses sujeitos como uma língua estrangeira o é para os ouvintes, apesar de a língua oficial do país estar presente em todos os locais por onde circulam os surdos. $\mathrm{O}$ processo de aprendizagem da leitura e da escrita, nas décadas passadas, foi visto como de grande dificuldade para o surdo. Resultados de trabalhos citados por Mendes e Novaes (2002) afirmam que o surdo é um mau leitor, quando o seu desempenho em compreensão de texto é comparado ao de seus pares ouvintes. Entre as dificuldades apresentadas pelo surdo no uso do português escrito, estão o pouco conhecimento de vocabulário, o uso da sintaxe, o pouco conhecimento da linguagem figurada e a realização de inferências.

Os estudos sobre a escrita do surdo, especialmente até o final da década de 1990, foram marcados por comparações entre as características apresentadas pelos surdos e pelos ouvintes. Nesta perspectiva, é notória a defasagem que aqueles sujeitos apresentariam em relação a estes, em função do já mencionado não domínio da língua portuguesa pelos surdos. Algumas características relacionadas ao surdo, na perspectiva comparativa, têm sido apresentadas por Fernandes
(1990), Góes (1999) e Salles, Faulstich, Carvalho e Ramos (2004). Fernandes (1990) afirma que, entre as características da produção de textos das crianças surdas, estão o vocabulário bastante reduzido, a dificuldade no domínio de desinências verbais e nominais, o uso de verbo acompanhado inadequadamente de pronome, o uso do verbo estar no lugar de ter e vice-versa, a impropriedade no uso de preposições e na inserção de advérbios, o uso inadequado de verbos e o pouco domínio das estruturas de coordenação e subordinação. Corroborando essa posição, Góes (1999) cita a ocorrência de sequências de palavras que tendem a desrespeitar a ordem convencional da língua e de enunciados compostos por substantivos que, muitas vezes, substituem verbos; terminação verbal que não corresponde à pessoa do sujeito; inconsistência de modo e tempo verbal (terminação inadequada para tempo e pessoa do verbo); flexão inadequada de gênero e número em adjetivos e artigos e uso incorreto do pronome pessoal do caso oblíquo. Além destas características, segundo Salles e cols. (2004), os surdos podem apresentar dificuldade no uso do pretérito perfeito e imperfeito, falta de elementos formadores de palavras (afixos) e oposição ser/estar. Isto pode acontecer pela falta de experiência com textos escritos, com práticas de interpretação e produção textual (Sarrú, 2003).

No entanto, na primeira década do século XXI, percebe-se a tendência a se estudar os processos de leitura e escrita do surdo não em função da identificação das "incapacidades" ou dificuldades destes sujeitos em comparação com os ouvintes, mas em função da funcionalidade da sua escrita, especialmente, sob os aspectos de coesão e coerência (Andrade, 2007; Sampaio, 2004/2007; Silva, 2001). Desta forma, a compreensão da leitura, a coesão e a coerência textuais têm sido priorizadas em detrimento da forma como a escrita é produzida e de como a leitura é realizada, apesar de se relevar as questões morfossintáticas da língua.

Este estudo parte do pressuposto de que a coesão e a coerência textuais são pontos-chave para o desenvolvimento da escrita do surdo. Sabendo que a oralidade apresenta influência sobre o processo de coesão textual, tomou-se como base teórica a perspectiva da continuidade entre as modalidades oral e escrita da língua. Segundo Collins e Michaels (1991) e Marcuschi $(1998,2004)$, a fala e a escrita não formam dois extremos, mas um continuum distribuído em uma escala de parâmetros empiricamente detectáveis. Sabendo que fala e a escrita formam um continuum, pode-se 
inferir que as características presentes na fala podem estar presentes na escrita e vice-versa. Segundo Andrade (2007), seguindo a tendência em estudar a relação entre a fala e a escrita na perspectiva do continuum "marcuschiano", as marcas de oralidade estão presentes na escrita dos surdos, mesmo na dos surdos não-oralizados e, portanto, podem ser um importante facilitador da compreensão do conteúdo desta escrita, seja por outros surdos ou por ouvintes. Desta forma, e considerando a premissa de que as marcas de oralidade são um fator de coesão textual, a pergunta que motivou a realização deste estudo foi: o fato de utilizar marcas de oralidade na escrita faz com que esta seja mais compreensível (especialmente sob o aspecto da coesão) pelo ouvinte?

Segundo Marcuschi (2002), podem ser consideradas marcas de oralidade os marcadores discursivos, as repetições, as correções ${ }^{2}$ e os parafraseamentos. Jubran (2006), Jubran e cols. (1996), Marcuschi (2002) e Risso, Silva e Urbano $(1997,2006)$ afirmam que, aos marcadores discursivos, pode-se atribuir a condição de uma categoria pragmática bem consolidada no funcionamento da linguagem. Essas estruturas têm por função promover a articulação de segmentos do discurso, atuando na organização tópica, estabelecendo aberturas, encaminhamentos, retomadas e fechos de tópico e na organização da estrutura da frase, unindo orações ou seus segmentos internos. Como exemplos de tais marcadores, podem ser citados: agora, então, realmente, depois, ainda agora, e, $e$ aí, às vezes, e tem mais, e depois então, mas, quer dizer, aliás, logo, ou, em outras palavras, finalmente (Jubran, 2006; Risso, 2006).

De acordo com Silva (2001), o fenômeno linguístico da repetição desempenha um papel crucial desde as primeiras etapas da aquisição da linguagem e da socialização. Marcuschi (1997, p. 97) define funcionalmente esta marca de oralidade como "a produção de segmentos discursivos idênticos ou semelhantes duas ou mais vezes no âmbito de um mesmo evento comunicativo". Corroborando, Tannen (1987) afirma que a repetição contribui para o estabelecimento do envolvimento entre os interlocutores nos aspectos de produção e compreensão conversacional. Para Jubran (2006), a repetição, como estratégia, pode introduzir, reintroduzir, manter ou delimitar tópicos. Para Marcuschi (2006), mais do que uma simples característica da fala, a repetição é uma das estratégias de formulação textual mais presentes na oralidade. Este aspecto é, primordialmente, uma prova da naturalidade do texto oral e uma característica essencial não só da interação verbal, mas também da produção linguística resultante dessa interação, seja ela dialógica ou monológica (Marcuschi, 2002).

Por apresentar uma maleabilidade funcional, a repetição assume um variado conjunto de funções: pode dar ênfase; reiterar um fato; contribuir para a organização discursiva e a monitoração da coerência textual; favorecer a coesão e a geração de sequências mais compreensíveis; dar continuidade à organização tópica e auxiliar nas atividades interativas (Marcuschi, 2006). As repetições, desta forma, atuam em vários planos: da coesividade, da compreensão, da continuidade tópica, da argumentatividade e da interatividade (Marcuschi, 1997, 2006).

Jubran e cols. (1996) e Hilgert (2006) definem o parafraseamento como uma estratégia de construção textual que se situa entre as atividades de reformulação onde novos enunciados remetem a anteriores, modificando-os parcial ou totalmente, mantendo uma relação de equivalência semântica entre os enunciados e retomando o conteúdo anteriormente exposto. Desta forma, o parafraseamento sempre implica algum deslocamento de sentido, com uma relação de equivalência semântica entre o enunciado-origem ou matriz e outro enunciado linguístico (a paráfrase) que o reformula (Hilgert, 1997).

Sendo as marcas de oralidade um fator de coesão textual e sabendo que os surdos as utilizam (Andrade, 2007), o objetivo geral deste estudo foi investigar a relação entre o uso de marcas de oralidade na escrita pelo surdo e a compreensão desta escrita por ouvintes.

\section{MÉTODO}

\section{Participantes}

Participaram do estudo 26 sujeitos ouvintes, de ambos os sexos, com idade entre 19 e 31 anos, estudantes de uma universidade pública do Estado de Pernambuco.

\section{Material e procedimentos}

A partir do banco de dados de Andrade (2007), foram selecionados vinte fragmentos de escrita produzidos por surdos e ouvintes, estudantes do Ensino Médio, com idade entre 17 e 38 anos. Todos os surdos apresentavam perda auditiva de grau severo ou profundo bilateral e eram oralizados ou não-oralizados. Entre os vinte fragmentos, quinze foram produzidos por surdos (cinco apresentavam mais de uma marca de oralidade - seja marcador discursivo, repetição ou 
parafraseamento -, cinco apresentavam apenas uma marca de oralidade e cinco não apresentavam marcas de oralidade) e cinco, por ouvintes. Todos os cinco fragmentos produzidos por ouvintes apresentavam mais de uma marca de oralidade. Os fragmentos foram selecionados considerando a ocorrência ou não de marcas de oralidade e a sua quantidade (mais de uma marca ou apenas uma marca). Os fragmentos utilizados eram compostos por uma pergunta e uma resposta acerca do dia-a-dia educacional, como dificuldades apresentadas na escola, comunicação com os colegas ouvintes (para os surdos) e com os colegas surdos (para os ouvintes), preconceito com a surdez e suges- tões para facilitação da aprendizagem do português pelo surdo.

As Figuras 1 a 4 ilustram exemplos de fragmentos apresentados aos sujeitos ouvintes. A Figura 1 ilustra um exemplo de escrita com mais de uma marca de oralidade (todos marcadores discursivos, em destaque no texto), a Figura 2 ilustra um exemplo de escrita com apenas uma marca de oralidade (uma redução parafrásica), a Figura 3 ilustra um exemplo de escrita sem marca de oralidade e a Figura 4 ilustra um exemplo de escrita produzida por ouvintes, em que há a ocorrência de três marcadores discursivos.

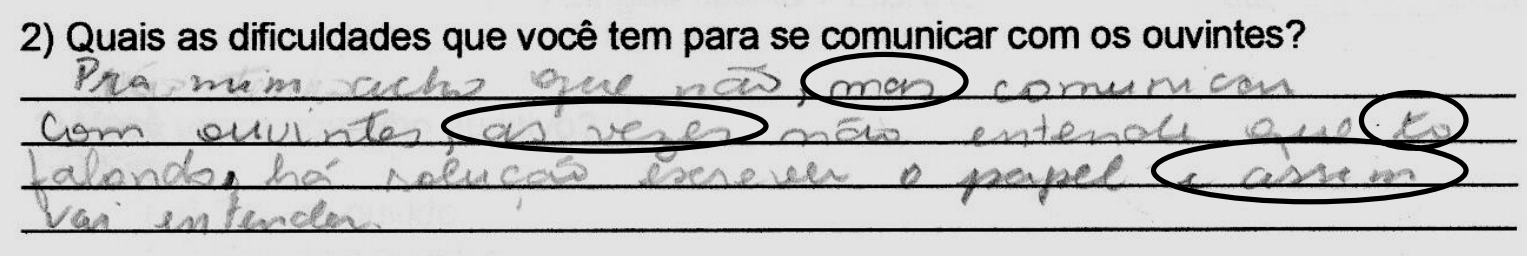

Figura 1. Exemplo de fragmento com mais de uma marca de oralidade 3.

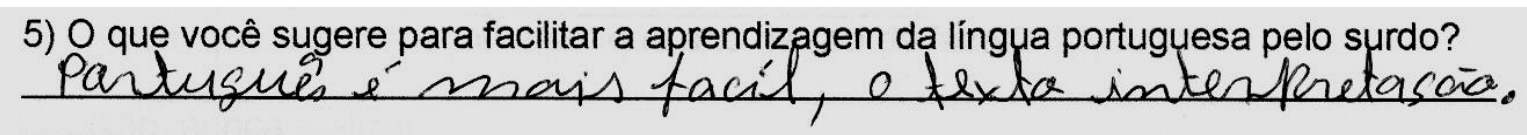

Figura 2. Exemplo de fragmento com uma marca de oralidade4.

5) $O$ que você sugere para facilitar a aprendizagem da língua portuguesa pelo surdo?

Q Portugesa minito estuda ma mais ofe menos

Figura 3. Exemplo de fragmento sem marca de oralidade 5 .

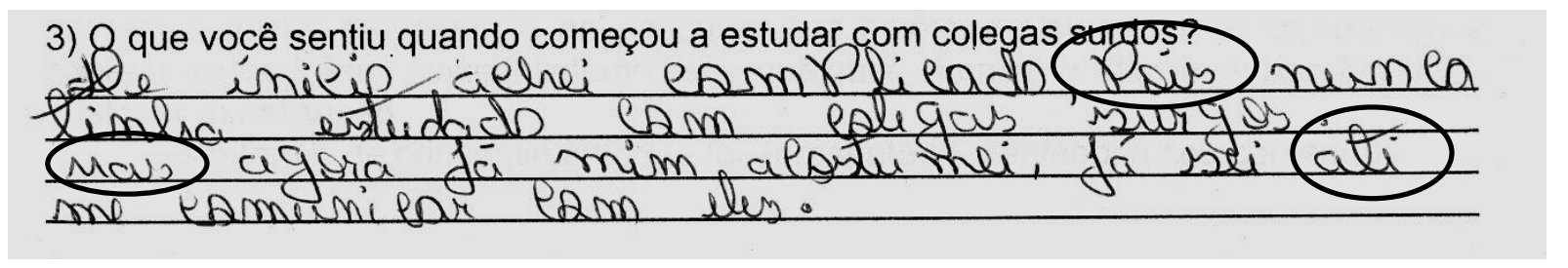

Figura 4. Exemplo de fragmento de escrita de ouvintes ${ }^{6}$. 
Os vinte fragmentos de escrita selecionados foram apresentados aos 26 participantes deste estudo com a instrução de analisá-los sob o ponto de vista da compreensão do conteúdo e não com relação a questões gramaticais ou ortográficas, atribuindo escores de 0 (caso não compreendessem o que foi escrito) a 10 (se compreendessem o conteúdo da escrita na sua totalidade). Apesar de algumas respostas terem dado pista sobre o fato de ter sido produzido por um surdo ou por um ouvinte, os participantes não foram informados sobre quais eram os cinco fragmentos produzidos por ouvintes para que não se influenciasse a sua decisão sobre a pontuação destinada aos fragmentos.

\section{Análise dos dados}

Foi calculada a média aritmética dos escores atribuídos pelos participantes à compreensão dos textos escritos pelos surdos e pelos ouvintes. As médias dos quatro grupos de fragmentos foram arredondadas para duas decimais e comparadas através de um teste de proporções para amostras independentes.

\section{Considerações éticas}

Os participantes da pesquisa foram solicitados a ler e, caso concordassem com o seu conteúdo, assinar um termo de consentimento livre e esclarecido (TCLE). Este termo informou os sujeitos sobre a ausência de custos e desconfortos para a sua integridade física e moral, assim como a possibilidade de ter suas informações retiradas do estudo no momento em que desejassem, sem que fossem, de qualquer forma, penalizados por isso.

\section{RESULTADOS E DISCUSSÕES}

Na Tabela 1, está apresentada a frequência e o percentual referentes a cada escore, considerando cada um dos quatro grupos de fragmentos. Pode-se perceber que os participantes do presente estudo (ouvintes) manifestaram, através da atribuição de mais baixos escores, maior dificuldade em compreender a escrita dos surdos em comparação à escrita de ouvintes. Estes, por terem maior acesso à modalidade oral da língua, apresentam, mais naturalmente, marcas de oralidade na escrita, o que promove uma maior coesão textual e, consequentemente, facilita a compreensão de sua escrita (Andrade, 2007). Além disso, quando comparados os três grupos de surdos, percebe-se uma relação diretamente proporcional entre a quantidade de marcas de oralidade e os escores atribuídos. Os escores iguais ou superiores a sete, por exemplo, foram fornecidos a $50,7 \%$ dos fragmentos de escrita com mais de uma marca de oralidade, a 21,6\% dos fragmentos de escrita com uma marca e a $17,7 \%$ dos fragmentos sem marca de oralidade. Todos os fragmentos produzidos por ouvintes receberam escores iguais ou superiores a sete.

TABELA 1

Frequência e Percentual de Escores para Cada Grupo

Surdos

\begin{tabular}{|c|c|c|c|c|c|c|c|c|}
\hline \multirow[t]{2}{*}{ Escore } & \multicolumn{2}{|c|}{ Mais de uma marca } & \multicolumn{2}{|c|}{ Uma marca } & \multicolumn{2}{|c|}{ Nenhuma marca } & \multicolumn{2}{|c|}{ Ouvintes } \\
\hline & Freq. & $\%$ & Freq. & $\%$ & Freq. & $\%$ & Freq. & $\%$ \\
\hline 0 & 6 & 4,6 & 20 & 15,4 & 25 & 19,2 & 0 & 0,00 \\
\hline 1 & 7 & 5,4 & 15 & 11,5 & 18 & 13,8 & 0 & 0,00 \\
\hline 2 & 6 & 4,6 & 9 & 6,9 & 10 & 7,7 & 0 & 0,00 \\
\hline 3 & 14 & 10,9 & 15 & 11,5 & 11 & 8,5 & 0 & 0,00 \\
\hline 4 & 7 & 5,4 & 19 & 14,6 & 15 & 11,5 & 0 & 0,00 \\
\hline 5 & 6 & 4,6 & 14 & 10,8 & 17 & 13,1 & 0 & 0,00 \\
\hline 6 & 18 & 13,8 & 10 & 7,7 & 11 & 8,5 & 0 & 0,00 \\
\hline 7 & 12 & 9,2 & 11 & 8,5 & 6 & 4,6 & 1 & 0,8 \\
\hline 8 & 16 & 12,3 & 8 & 6,2 & 10 & 7,7 & 7 & 5,4 \\
\hline 9 & 19 & 14,6 & 3 & 2,3 & 4 & 3,1 & 16 & 12,3 \\
\hline 10 & 19 & 14,6 & 6 & 4,6 & 3 & 2,3 & 106 & 81,5 \\
\hline Total & 130 & 100,0 & 130 & 100,0 & 130 & 100,0 & 130 & 100,0 \\
\hline
\end{tabular}

Nota. Freq. $=$ Frequência; \% = Percentual. 
As médias aritméticas dos escores atribuídos a cada um dos quatro grupos analisados estão apresentadas na Tabela 2. Observa-se que o escore médio obtido para a escrita dos ouvintes $(9,74)$ supera em mais de 3,50 o escore médio obtido para a escrita dos surdos com mais de uma marca de oralidade. Quando comparadas as médias dos escores atribuídos à escrita dos ouvintes e à escrita dos surdos com mais de uma marca de oralidade, foi observada uma diferença altamente significativa $(z=3,992, p<0.001)$, ou seja, os escores atribuídos à escrita dos ouvintes (fortemente marcada pela oralidade) foram significativamente maiores do que os atribuídos à escrita dos surdos, quando estes utilizavam mais de uma marca de oralidade. Isto sugere que a utilização das marcas de oralidade na escrita pode ser um fator importante para a coesão textual. Desta forma, a escrita dos ouvintes, com mais marcas de oralidade, foi significativamente mais compreensível do que a escrita dos surdos, mesmo quando estes utilizam mais de uma marca de oralidade. Além disso, os escores atribuídos à escrita dos surdos com mais de uma marca de oralidade também foram significativamente maiores do que a escrita com apenas uma marca de oralidade $(z=2,594, p<0.001)$. Isto sugere que a escrita de surdos com mais de uma marca de oralidade é mais compreensível do que a escrita com apenas uma marca de oralidade. Segundo Andrade (2007), as marcas de oralidade constituem um fator de coesão textual e facilitam o processo de compreensão do texto. No entanto, não foi verificada diferença estatisticamente significativa entre os escores atribuídos à escrita com uma marca e sem marca de oralidade $(z=0,421, p=$ n.s. $)$. Pode-se sugerir que, apesar de as marcas de oralidade serem estruturas importantes para a compreensão da escrita e, consequentemente, influenciarem o estabelecimento da coesão textual, a utilização de uma marca de oralidade isoladamente não exerce o efeito necessário para que esta escrita possa ser adequadamente compreendida.

TABELA 2

Médias Aritméticas dos Escores Atribuídos à Escrita dos Grupos

\begin{tabular}{llc}
\hline & Grupo & Média \\
\hline \multirow{3}{*}{ Surdos } & Mais de uma marca de oralidade & 6,15 \\
& Uma marca de oralidade & 3,94 \\
& Nenhuma marca de oralidade & 3,62 \\
& Ouvintes & 9,74 \\
\hline
\end{tabular}

\section{CONCLUSÕES}

Verificou-se uma relação direta entre a utilização de marcas de oralidade na escrita por surdos e a compreensão desta escrita por ouvintes. A escrita dos surdos, foco do presente estudo, foi mais compreensível pelos ouvintes quando continha mais de uma marca de oralidade. A escrita com mais de uma marca de oralidade foi significativamente mais compreensível do que a escrita com apenas uma marca de oralidade. Existe, ainda, a possibilidade de a escrita com mais de uma marca de oralidade produzida pelos surdos se aproximar (com relação à estrutura gramatical) da escrita produzida por ouvintes ter influenciado o julgamento dos ouvintes participantes com relação à compreensão dos fragmentos de escrita apresentados. Já a escrita com uma marca e sem marca de oralidade não apresentaram diferença significativa com relação à sua compreensão pelos ouvintes. Em função da diferença não-significativa entre a compreensão da escrita de surdos com uma marca e sem marca de oralidade, pode-se afirmar que o uso de apenas uma marca de oralidade na escrita pode não apresentar efeito (ou apresentar pouco efeito) sobre a coesão textual e, consequentemente, sobre a compreensão do conteúdo da escrita.

A utilização de marcas de oralidade, embora seja em parte condenada no processo de escolarização, facilita a compreensão do conteúdo da escrita dos surdos pelos ouvintes, em função da otimização da coesão textual da escrita destes sujeitos. Desta forma, ao usar marcas de oralidade na escrita, os surdos tornam o texto mais coeso aos olhos do ouvinte. Deve-se ressaltar, no entanto, que as marcas de oralidade não são estruturas absolutamente imprescindíveis para um texto compreensível, mas acredita-se que a sua presença em quantidade adequada aumenta a probabilidade de este texto ser compreendido pelo leitor, tendo em vista que estas estruturas se relacionam à coesão textual. Apesar de considerarmos a língua de sinais a língua mais adequada ao desenvolvimento do surdo, o 
desenvolvimento da língua oral é uma importante forma de comunicação com o mundo de ouvintes, concretizando, assim, o bilinguismo de forma plena (língua de sinais associada à língua padrão do país nas modalidades oral e escrita). Esta filosofia educacional, tal qual é proposta na teoria, poderia proporcionar um maior acesso do surdo à língua padrão do país e, com isso, uma maior facilidade em lidar com a escrita nesta língua. Desta forma, além de ser desejável o desenvolvimento da oralidade, dependendo do objetivo do texto a ser produzido pelo surdo, pode ser incentivado o uso de marcas desta oralidade na escrita, como estratégia de otimização da coesão textual dos surdos, embora o "escrever como se fala", em geral, seja reprimido na escola tradicional.

\section{REFERÊNCIAS}

Aimard, P. (1998). O surgimento da linguagem na criança (C. Schilling, Trad.). Porto Alegre: Artmed.

Andrade, W. T. L. (2007). A relação entre oralidade e escrita em língua portuguesa no surdo. Dissertação de mestrado nãopublicada, Universidade Católica de Pernambuco.

Cabral, G. (2005). Perspectivas para uma pedagogia bilíngue: A educação infantil e o ensino fundamental no centro SUVAG de Pernambuco. Em Centro SUVAG de Pernambuco (Org.), Estudos surdos: Novas perspectivas (pp. 15-27). Recife: Centro SUVAG de Pernambuco.

Cavalcanti, E. M. S. (2001). A escrita de uma criança surda: Uma análise alternativa. Dissertação de mestrado não-publicada, Pontifícia Universidade Católica de São Paulo.

Collins, J., \& Michaels, S. (1991). A fala e a escrita: Estratégias de discurso e aquisição da alfabetização. Em J. Cook-Gumperz (Org.), A construção social da alfabetização (D. Batista, Trad.) (pp. 242-258). Porto Alegre: Artes Médicas.

Costa, D. A. F. (2002). Um novo olhar sobre a singularidade: Compreendendo a gênese da escrita em aprendizes surdos. Revista Brasileira de Educação Especial, 8(1), 75-92

Fernandes, E. (1990). Problemas linguísticos e cognitivos dos surdos. Rio de Janeiro: Agir.

Fernandes, E. (2003). Linguagem e surdez. Porto Alegre: Artmed.

Friães, H. M. S., \& Pereira, M. C. C. (2000). Compreensão de leitura e surdez. Em C. B. F. Lacerda \& M. C. R. Góes (Orgs.), Surdez: Processos educativos e subjetividade (pp. 113-122). São Paulo: Lovise.

Góes, M. C. R. (1999). Linguagem, surdez e educação. Campinas: Autores Associados.

Goldfeld, M. (2002). A criança surda: Linguagem e cognição numa perspectiva sócio-interacionista ( $2^{\mathrm{a}}$ ed.). São Paulo: Plexus.

Hilgert, J. G. (1997). As paráfrases na construção do texto falado: O caso das paráfrases em relação paradigmática com suas matrizes. Em I. G. V. Koch (Org.), Gramática do português falado (2 $2^{\mathrm{a}}$ ed.) (pp. 131-147). Campinas: UNICAMP/FAPESP.
Hilgert, J. G. (2006). Parafraseamento. Em C. C. A. S. Jubran \& I. G. V. Koch. (Orgs.), Gramática do português culto falado no Brasil (pp. 275-299). Campinas: UNICAMP.

Jubran, C. C. A. S. (2006). Tópico discursivo. Em C. C. A. S. Jubran \& I. G. V. Koch (Orgs.), Gramática do português culto falado no Brasil (pp. 89-132). Campinas: UNICAMP.

Jubran, C. C. A. S., Urbano, H., Koch, I. G. V., Fávero, L. L., Marcuschi, L. A., Travaglia, L. C., Silva, M. C. P. S., Santos, M. C. O. T., Andrade, M. L. V., Risso, M. S., \& Aquino, Z. G. O. (1996). Organização tópica da conversação. Em R. Ilari (Org.), Gramática do português falado ( $3^{\mathrm{a}}$ ed.) (pp. 351-375). Campinas: UNICAMP.

Marcuschi, L. A. (1997). A repetição na língua falada como estratégia de formulação textual. Em I. G. V. Koch (Org.), Gramática do português falado ( $2^{\mathrm{a}}$ ed.) (pp. 95-126). Campinas: UNICAMP/FAPESP.

Marcuschi, L. A. (1998). Nove teses para uma reflexão sobre a valorização da fala no ensino da língua. Revista da Associação de Pós-Graduação e Pesquisa em Letras e Linguística, 4(3), 325-332.

Marcuschi, L. A. (2002). A presença da repetição na fala e algumas perspectivas de tratamento. Investigações: Lingüística e Teoria Literária, 2, 31-47.

Marcuschi, L. A. (2004). Da fala para a escrita: Atividades de retextualização ( $5^{\mathrm{a}}$ ed.). São Paulo: Cortez.

Marcuschi, L. A. (2006) Repetição. Em C. C. A. S. Jubran \& I. G. V. Koch. (Orgs.), Gramática do português culto falado no Brasil (pp. 219-254). Campinas: UNICAMP.

Mendes, B. C. A., \& Novaes, B. C. A. C. (2002). Oficina de leitura com adolescentes surdos: Uma proposta fonoaudiológica. Em A. P. Berberian, G. A. Massi \& A. C. Guarinello (Orgs.), Linguagem escrita: Referenciais para a clínica fonoaudiológica (pp. 125-159). São Paulo: Plexus.

Quadros, R. M. (1997). Educação de surdos: A aquisição da linguagem. Porto Alegre: Artes Médicas.

Risso, M. S. (2006). Marcadores discursivos basicamente sequenciadores. Em C. C. A. S. Jubran \& I. G. V. Koch (Orgs.), Gramática do português culto falado no Brasil (pp. 427-496). Campinas: UNICAMP.

Risso, M. S., Silva, G. M. O., \& Urbano, H. (1997). Marcadores discursivos: Traços definidores. Em I. G. V. Koch (Org.), Gramática do português falado ( $2^{\mathrm{a}} \mathrm{ed}$.) (pp. 21-94). Campinas: UNICAMP/FAPESP.

Risso, M. S., Silva, G.M.O., \& Urbano, H. (2006). Traços definidores dos marcadores discursivos. Em C. C. A. S. Jubran \& I. G. V. Koch (Orgs.), Gramática do português culto falado no Brasil (pp. 403-425). Campinas: UNICAMP.

Russo, I. C. P. (1999). Orientação a pais de crianças deficientes auditivas. Em N. Caldas, S. Caldas Neto \& T. Sih (Orgs.), Otologia e audiologia em pediatria (pp. 239-245). Rio de Janeiro: Revinter.

Salles, H. M. M. L., Faulstich, E., Carvalho, O. L., \& Ramos, A. A. L. (2004). Ensino de língua portuguesa para surdos: Caminhos para a prática pedagógica. Brasília: MEC/SEESP.

Sampaio, M. J. A. (2004). A escrita de surdos universitários vista sob o enfoque da teoria interacionista em aquisição de linguagem. Monografia de especialização não-publicada, Universidade Católica de Pernambuco. 
Sampaio, M. J. A. (2007). A construção de textos na escrita de surdos: Estratégias do sujeito na transição entre sistemas linguísticos. Dissertação de mestrado não-publicada, Universidade Federal da Paraíba.

Sarrú, S. L. (2003). Estudio descriptivo acerca de los recursos lingüísticos utilizados en la organización discursiva/textual de narraciones escritas realizadas por jóvenes sordos hablantes de lengua de señas en proceso de alfabetización. Monografia de licenciatura não-publicada, Universidad Nacional de Rosario.

Silva, D. E. G. (2001). A repetição em narrativas de adolescentes: Do oral ao escrito. Brasília: UnB/Plano.
Silva, M. P. M. (2001). A construção de sentidos na escrita do aluno surdo. São Paulo: Plexus.

Tannen, D. (1987). Repetition and variation as spontaneous formulaicity in conversation. Language, 63, 574-605.

Recebido: 09/10/2008

Última revisão: $20 / 01 / 2010$

Aceite final: $30 / 01 / 2010$

\section{Notas:}

1 Considerando o bilinguismo, filosofia educacional segundo a qual a língua de sinais deve ser a primeira língua do surdo, enquanto que a língua padrão do país, seja na modalidade oral ou escrita, deve ser desenvolvida como uma segunda língua.

2 As correções não foram consideradas neste estudo por não terem sido verificadas por Andrade (2007) na escrita de surdos. Isto pode ter ocorrido, segundo Marcuschi (2006), pelo fato de haver a possibilidade de revisão do conteúdo escrito que expõe apenas o produto final, enquanto que, da fala, nada se apaga.

3 Transcrição da escrita do fragmento: "Pra mim acho que não, mas comunicar com ouvintes, as vezes não entende que to falando, há solução escrever o papel e assim vai entender.”.

4 Transcrição da escrita do fragmento: "Português é mais fácil, o texto interpretação.".

5 Transcrição da escrita do fragmento: "O Portugesa muito estuda na mais ou menos dificuldades".

6 Transcrição da escrita do fragmento: "De início achei complicado, pois nunca tinha estudado com colegas surgos. mas agora já mim acostumei, já sei até me comunicar com eles.".

\section{Sobre os autores:}

Wagner Teobaldo Lopes de Andrade: Fonoaudiólogo, Mestre em Ciências da Linguagem pela Universidade Católica de Pernambuco, Doutorando em Linguística pela Universidade Federal da Paraíba, Professor Assistente do Departamento de Fonoaudiologia da Universidade Federal da Paraíba.

Marígia Ana de Moura Aguiar: Pós-doutorado pela University of Birmingham (Reino Unido), PhD em Psicolinguística pela Reading University (Reino Unido), Professora do Mestrado em Ciências da Linguagem da Universidade Católica de Pernambuco, Pesquisadora do CNPq.

Francisco Madeiro: Doutor em Engenharia Elétrica pela Universidade Federal da Paraíba, Professor do Mestrado em Ciências da Linguagem da Universidade Católica de Pernambuco.

Sandra Patrícia Ataíde Ferreira: Professora Adjunto do Departamento de Psicologia e Orientação Educacionais (Centro de Educação) e da Pós-graduação em Psicologia Cognitiva (Centro de Filosofia e Ciências Humanas) da Universidade Federal de Pernambuco.

Antonio Roazzi: PhD em Psicologia do Desenvolvimento pela University of Oxford (Inglaterra) e, atualmente, Coordenador do Programa de Pós-graduação em Psicologia Cognitiva da Universidade Federal de Pernambuco.

Endereço para correspondência: Wagner Teobaldo Lopes de Andrade - Departamento de Fonoaudiologia - Universidade Federal da Paraíba - Cidade Universitária - Campus I, Castelo Branco - 58051-900 João Pessoa - PB - Endereço eletrônico: wagner_teobaldo@yahoo.com.br 